\title{
An empirical supply chain measurement model for a national egg producer based on the supply chain operations reference model
}

\begin{abstract}
Authors:
Christian Pretorius ${ }^{1}$

George A. Ruthven ${ }^{1}$

Konrad von Leipzig ${ }^{1}$

\section{Affiliations:}

Department of Industrial Engineering, University of Stellenbosch, South Africa

\section{Correspondence to:}

George Ruthven

Email:

gar@sun.ac.za

\section{Postal address:}

Department of Industrial

Engineering, Private Bag X1,

Matieland 7602, South Africa

Dates:

Received: 22 Mar. 2013

Accepted: 23 Aug. 2013

Published: 14 Oct. 2013

How to cite this article: Pretorius, C., Ruthven, G.A. \& Von Leipzig, K., 2013, 'An empirical supply chain measurement model for a national egg producer based on the supply chain operations reference model' Journal of Transport and Supply Chain Management 7(1), Art. \#97, 13 pages. http://dx.doi.org/10.4102/ jtscm.v7i1.97
\end{abstract}

\section{Note:}

A pseudonym was used in order to protect the identity of the company discussed, as requested by them.

\section{Copyright:}

(C) 2013. The Authors.

Licensee: AOSIS

OpenJournals. This work

is licensed under the

Creative Commons

Attribution License.

Read online:
The management of a supply chain is both an offensive and defensive weapon that organisations can use to increase their competitive edge and capture a larger share of the market. In management science and supply chain management, multi-criteria decision making techniques have been used to solve a range of real-world problems. The problem is that many, if not most, companies in South Africa either do not have the required skills to use these decision-making techniques to improve or re-configure their supply chain, or they do not have a complete data set with which to model it effectively. In order to manage supply chains effectively, organisations at the very least need feedback on the performance of their entire supply chain. In this article, generic supply chain performance measures were used and a theoretical or empirical model was developed for the performance measurement of a national egg producer's supply chain. It focused on a managerial program for the identification and management of their supply chain with recommendations for applying a measurement model. The overall performance of the supply chain as well as the five different performance attributes was presented to management in a dashboard format. This article could be used as a basis for future studies of supply chain performance measurement and the model could be used as a foundation for developing an improved version, not only for the egg industry, but for other industries as well.

\section{Introduction}

\section{Notes on supply chain management}

The definition of a supply chain that will be used throughout this article is: 'the product life cycle processes comprising physical, information, financial, and knowledge flows whose purpose it is to satisfy end-user requirements with physical products and services from multiple, linked suppliers' (Ayers 2006).

Research indicates that even though most organisations manage functional areas within their supply chain, and even produce local optimal results in these areas, the overall result could be suboptimal (Bullinger, Kühner \& Van Hoof 2002). By managing functional areas separately, organisations limit their view in terms of overall integration of functions as well as stakeholders. The management of the entire supply chain allows for an overall improved result, and organisations that manage their entire supply chain tend to provide products of better quality. Furthermore, distinguishing between cost and non-cost measures (time, quality, flexibility and innovation) is important, as relying exclusively on cost indicators can produce a misleading picture of supply chain performance (Shepherd \& Günter 2005).

Gunasekaran, Patel and McGaughey (2004) stated that:

As organisations look to partner with their suppliers as well as their suppliers' suppliers, it is not surprising that they are not concerning themselves only with price when looking for suppliers, but rather for willing partners to work co-operatively in providing improved service, technological innovation and product redesign.

\section{Problem statement}

The local depot of a national egg-producing organisation, $\mathrm{SA} \mathrm{Egg}{ }^{1}$, required a measurement model that would enable management to evaluate the efficiency of their overall supply chain, not just the independent operational activities. Management traditionally managed the process functions of all the participating departments, but required a broader supply chain-type approach 
in order to streamline all activities. Thus, a project to develop a measurement model was initiated; the first phase was to examine the deliveries from the farms to the depots, the grading and packaging of the eggs and the delivery to supermarkets as a partial supply chain.

SA Egg is an egg producer serving a national market. It is mostly an agricultural firm that has been in operation for more than 50 years. The supply chain starts in Europe, where day-old-chicks (pullets and cockerels) are acquired from a breeder and shipped to their hatcheries in South Africa. Here they are raised for commercial use. Multiple generations are raised to ensure a commercial group of different ages that produce eggs of multiple sizes (medium, large, extra-large and jumbo). On the egg-producing commercial farms, the process is completely automated and there is a conveyor system that feeds the eggs from the coops to the collection point. The eggs are collected and then transported to a depot in every major city; they are labelled as ungraded eggs. At the depots, the eggs go through a grading process whereby they are categorised and packaged according to weight. Finally, the finished products are sent to the dispatch area, where they are selected for specific orders and then delivered to retail stores around the country.

An empirical model was thus developed (the developed model) and implemented as a performance-measurement system to evaluate the performance of SA Egg's supply chain from the focal point of their Cape Town depot. The developed model looks at a specific range, which is from the intake from the commercial farms to the delivery of the products to the retailers. This however excludes the supplier's suppliers, which are outside the scope of this project.

Huang, Sheoran and Keskar (2005) stated that:

Operating a supply chain is far different from running a standalone company, and so are the metrics. The supply chain can be looked at as an externalisation of business processes toward greater profitability. Trading partners, to a greater or lesser degree of formality, are linking their productive assets to gain efficiencies in cycle times, procurement, inventory, logistics, and cash flow. Given these relationships, how the partners measure effectiveness of their intertwined processes becomes quite different than assessing internal operations.

When an organisation can measure its supply chain performance, there are multiple advantages. A measurement tool enables an organisation to: derive a quantifiable value for the performance of the entire supply chain; compare their supply chain in parts or as a whole to the best practices of other supply chains within their industry; track their supply chain's performance over a period of time. This allows an organisation to create goals for the future and identify gaps or opportunities within its existing supply chain.

The aim of implementing supply chain management principles is to improve the supply chain's performance. The only way of identifying if there is an improvement is by measuring supply chain performance over time (Ayers 2006).
The starting point would thus be to identify key performance indicators (KPIs) that enable the tracking of the supply chain's performance.

\section{The research proposal}

Whilst traditional performance-measurement systems are based on costing and accounting, measuring performance in supply-chain networks requires a more balanced set of financial and non-financial measures at various points along the supply chain (Lohman, Fortuin \& Wouters 2004). Measurment of cost, time, quality, flexibility or innovation should also be noted, as well as whether they are quantitative or qualitative. Such a system was developed by the Supply Chain Council:

The supply chain council (SCC), a not-for-profit organization established in 1996 that now has over 650 organization members worldwide, has taken the initiative in developing such a model the supply chain operations reference (SCOR) model. It contains a standard description of management processes, a framework of relationships among the standard processes, standard metrics to measure process performance, management practices that produce best-in-class performance, and a standard alignment to software features and functionality (Huang et al. 2005).

The SCOR model also addresses the absence of a common vocabulary with which to facilitate communications among companies linked in the chain.

By definition, SCOR is used to develop a generic process that assists users in assessing whether they are doing the basic tasks well. Thus, the SCOR model is constructed with a general theme in mind and is not tailored to a specific business. The SCOR model is constructed from the top down, starting with five broad processes at Level 1: Plan, Source, Make, Deliver and Return. These are broken down into sub-processes at Levels 2 and 3. Levels 1, 2 and 3 therefore represent a common model for processes across industries. Level 4 and beyond are company specific, to be designed by each company to fulfil its strategies (Ayers 2006).

The Supply Chain Council continuously improves the SCOR model; Version 11 is the current version (Supply Chain Council 2012). In Version 11, the following benefits of adopting the SCOR model are listed:

- rapid assessment of supply chain performance

- clear identification of performance gaps

- efficient supply chain network redesign and optimisation

- enhanced operational control from standard core processes

- streamlined management reporting and organisational structure

- alignment of supply chain team skills with strategic objectives

- a detailed game plan for launching new businesses and products

- systematic supply chain mergers that capture projected savings.

Table 1 lists the key performance indicators (KPIs) for a food industry supply chain. It is divided into three levels: the 
bottom level consists of the processes and their KPIs, next is the organisational level and relevant KPIs, at the top is the supply chain network level and relating KPIs. All of the KPIs have a brief explanation (Van der Vorst 2000).

\section{Possible approaches for measuring supply chain performances}

Having established a good foundation of possible performance indicators, the next step is to decide on the appropriate technique or model, for the chosen indicators, with which to measure the performance of a supply chain. Specific models that were evaluated for the given situation included SCOR, the Balanced Scorecard (Kaplan \& Norton 1992) and Supply Network Scorecards (Bullinger et al. 2002). For this initial phase of the project, it was decided, for various reasons, to base the measurements on the SCOR model. The reasons included managements desire to use the tool to benchmark themselves against possible competitors, so a broad-based standardised model was preferred over a more tailored approach. SCOR attributes were thus utilised to develop a dashboard-type management tool.

\section{Process dashboards}

Dashboards consist of a selection of performance metrics that are presented in graphical form. They include, for instance, colour-coding of trend lines and alarms in the form of exclamation marks to show when key indicators are approaching a problem level. Although a performance dashboard is not a measurement technique per se, it does represent a summary of performance indicators that have been selected by the user to display certain information about the process it represents.

\section{Supply chain performance measurement for SA Egg}

\section{Development of the model}

The foundation of the model was based on the five core performance attributes identified by SCOR: reliability, responsiveness, agility, costs and asset management (Figure 1). The model branches out and measures the five SCOR Level 1 processes for each of the performance attributes that were identified within the supply chain: plan, source, make, deliver and return. Finally, by allocating key performance indicators (KPIs) to each of the SCOR processes from a combination of SCOR metrics, as well as other KPIs identified in literature, the lowest level performance measures were created by the authors in conjunction with management.

\section{Development of the reliability leg}

Supply chain reliability can simply be described as the percentage of time that things turn out as expected. The components of the reliability leg of this model consisted of variables that can be measured throughout the supply chain.

\section{Development of the responsiveness leg}

Supply chain responsiveness can be described as the speed at which the supply chain provides products to the final customer. The components of the responsiveness leg of this model consisted of variables that may be more difficult to measure.

\section{Development of the agility leg}

Supply chain agility is a performance attribute that is more difficult to apply to the egg industry as it is for other industries, as the laying of eggs is a natural and then automatic process once started - it can only be stopped by culling the source. The description of supply chain agility as it is used in this model is the ability or degree to which the supply chain can supply products to customers at different levels of demand whilst not compromising price, quality, or customer service. Components of the agility leg of this model consisted of aspects such as product mix or volume flexibility over which the egg producing supply chain has no or very little control.

\section{Development of the cost leg}

Supply chain cost is the cost of the entire supply chain. This includes the planning, managing, sourcing, making, delivering, supporting and warehousing costs of the supply chain. Managing the entire supply chain's total cost is important since this is how true-value is created for the customer. The supply chain cost performance attribute is a supply-chain-wide measurment and it is important to capture it holistically, thus the KPIs identified seem very basic, but they capture a very large group of Level 2 metrics.

\section{Development of the asset management leg}

Supply chain asset management is the ability or the degree to which the assets of the supply chain are efficiently utilised. There are three main KPIs identified by SCOR: first is cashto-cash cycle time. The second is inventory days of supply of raw materials, work-in-progress and finished goods, each

TABLE 1: List of key performance indicators within a food industry supply chain.

\begin{tabular}{|c|c|c|}
\hline Level & Performance indicator & Explanation \\
\hline \multirow[t]{5}{*}{$\begin{array}{l}\text { Supply chain } \\
\text { network }\end{array}$} & Product availability on shelf & $\begin{array}{l}\text { Presence of a large assortment } \\
\text { and no stock-outs }\end{array}$ \\
\hline & Product quality & Remaining product shelf life \\
\hline & Responsiveness & $\begin{array}{l}\text { Order cycle time of the supply } \\
\text { chain }\end{array}$ \\
\hline & Delivery reliability & $\begin{array}{l}\text { Meeting guaranteed delivery } \\
\text { times }\end{array}$ \\
\hline & Total supply chain cost & $\begin{array}{l}\text { Sum of all costs in the supply } \\
\text { chain }\end{array}$ \\
\hline \multirow[t]{5}{*}{ Organisation } & Inventory level & Number of products in store \\
\hline & Throughput time & $\begin{array}{l}\text { Time needed to perform a chain } \\
\text { of business processes }\end{array}$ \\
\hline & Responsiveness & $\begin{array}{l}\text { Flexibility of the organisation: } \\
\text { Lead time }\end{array}$ \\
\hline & Delivery reliability & $\begin{array}{l}\text { Percentage orders delivered on } \\
\text { time and in right quantity }\end{array}$ \\
\hline & Total organisational cost & $\begin{array}{l}\text { Sum of all process costs in the } \\
\text { specific organisation }\end{array}$ \\
\hline \multirow[t]{4}{*}{ Process } & Responsiveness & Flexibility of the process \\
\hline & Throughput time & $\begin{array}{l}\text { Time needed to perform the } \\
\text { process }\end{array}$ \\
\hline & Process yield & Outcome of the process \\
\hline & Process cost & Cost when executing the process \\
\hline
\end{tabular}

Source: Van der Vorst, J.G.A.J., 2000, Effective food supply chains: Generating, modelling and evaluating supply chain scenarios, pp. 50-53, PhD thesis, Wageningen University, viewed 11 June 2011, from http://www.library.wur.nl/wda/dissertations/dis2841.pdf 


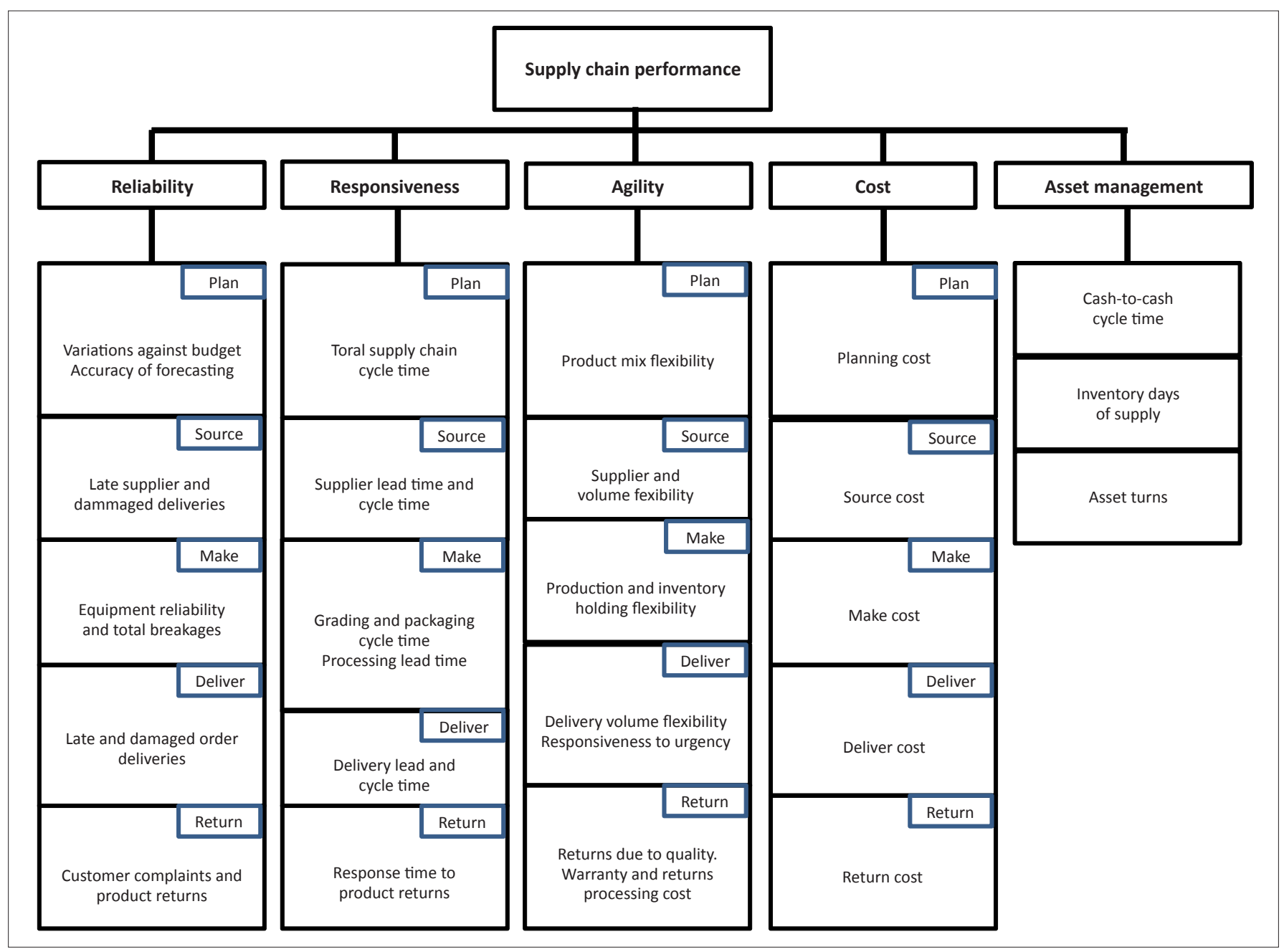

Source: Supply Chain Council 2012

FIGURE 1: Five core attributes identified by SCOR as presented to management

classified separately. The last KPI is asset turns, which is used to display the ratio of the amount invested in assets (fixed assets and working capital) for every one Rand of revenue received by an organisation.

\section{Proposed supply chain performance- measurement model for the egg industry}

By following the proposed structure above, the five different legs were developed further with regards to the eggproducing organisation. This involved the description of each leg within the framework of the organisation, as well as the composition of each in terms of performance indicators. The performance indicators used were given a working definition, as well as equations where applicable. The result was a model that facilitates the performance measurement of the egg organisation's supply chain; reliability, responsiveness, agility, cost and asset management were all evaluated.

\section{Configuring the model}

The steps for the development of the empirical performancemeasurement system based on the proposed model will now be described. This will be followed by how a supply chain performance-measurement system for SA Egg was created.

\section{Steps for the development of the system}

Not all performance indicators have the same units of measurement, nor do they measure the same aspects of a supply chain. In order to be able to calculate the overall performance of the supply chain, each of these performance indicators has to be standardised and made dimensionless. In order to award each performance indicator with a quantifiable dimensionless value, the process used to calculate each indicator needs to have the following: an input value, a target value and a tolerance controlling or adjustment value. The values used in this study were either supplied by the company or approximations were made based on own observations.

\section{Setting targets}

An important attribute of each performance indicator is that it should be quantifiable and, by either the calculation or summation thereof, be presented in a singular value. Therefore, even though they are all different, they all have a single value that can be gauged against a specific target value. For example, the number of customer complaints received each month should be less than five. Although this might seem basic, it allows an organisation to measure 
itself according to its short-term, medium-term and longterm goals. This also enables the organisation to compare itself to other organisations' supply chains; these include the organisations in the same industry as well as other industries.

\section{Rating factors}

After having set a specific target for a performance indicator, the next step is to determine how to score a certain value with regards to the target. What constitutes $80 \%$ or $90 \%$ of customer complaints if the target is five per month? This is where a proposed rating factor is introduced to standardise the score.

There are two questions that need to be considered when deciding on the value of a rating factor: the first is how realistic the value is and the second is the level of tolerance for the performance indicator in question. The answer to each will differ from industry to industry and in this case it was applied by using a trial and error approach in consultation with management. The proposed method for scoring a performance indicator out of 10 is calculated with the following equation:

Performance Score $=10-\frac{/ \text { Input Value }- \text { Target Value / }}{\text { Rating Factor }}$ [Eqn 1]

\section{An example of a performance indicator element in the system}

To illustrate the above mentioned concept, the example of customer complaints was used. A target value of five customer complaints per month was set, and a rating factor of five was decided. This means that $10 \%$ would be subtracted for every five customer complaints above that of the target. For the input value, the number of customer complaints for the month of July 2011 was used. In July 2011 SA Egg received 26 customer complaints; the performance score was calculated by the following equation:

Customer Complaints $=10-\frac{26-5}{5}=5.8$ out of 10

The performance score of the customer complaints performance indicator gauged the amount of customer complaints received in July 2011 against the target value. The score was not only expressed in a dimensionless number, but it also allowed SA Egg to quantify the contribution of the customer complaints performance indicator to the overall performance of their supply chain. By increasing either the target value (an increase in tolerance towards complaints if it's not an important issue in the egg producer's supply chain), or the rating factor, the customer complaints outcome would be improved. To make the changes (up or down) would require full co-operation by all the individual supply chain managers. The following illustration (Table 2) presents the user interface of the prototype for the supply chain performance-measurement system for the customer complaints performance indicator (part of the supply chain reliability leg) in Microsoft Excel (Microsoft, USA).
TABLE 2: A performance indicator.

\begin{tabular}{ll}
\hline Factors & Indicator \\
\hline Customer complaints performance score & 5.8 \\
Number of complaints & 26.0 \\
Target & 5.0 \\
Rating factor & 5.0 \\
\hline
\end{tabular}

\section{A performance-measurement system developed for SA EGG's supply chain}

There are a few key aspects to note before discussing the model in detail.

By briefly comparing the developed model (Figure 2) with the complete SCOR model (Figure 1), the first thing to notice is the difference in the amount of performance indicators represented by each model. The developed model only measures 18 performance indicators whereas the complete SCOR model measures 35. Although the difference might seem large, it is more informative to notice that the developed model measures 17 of the 23 process areas that the SCOR model recommends (see Figure 1). This provides some reassurance that the developed model does measure the majority of process areas representing the five performance attributes of SCOR. Each leg of the developed model will now be discussed.

\section{Reliability}

Supply chain reliability is the ability to perform tasks as expected. Due to various operational reasons, only six KPIs were implemented and used in the prototype. In some cases, such as with the accuracy of the forecasting KPI, management claimed not to do any forecasting and that they operated purely in a reactive nature. In other cases, like the late supplier delivery KPI, the concept of late arrivals seemed odd to management who stated that their custom was 'trucks arrive when they arrive'. Since SA Egg owns a large portion of their supply chain, management did not see any benefit in having their trucks arrive at a scheduled time as it was their practice to leave the farm once fully loaded. Although it would be fairly easy to install such a system to capture the data, management felt that there would be very little operational use for the data. In other cases, KPIs needed to be transformed due to the difficult nature of obtaining the data, such as the case of the re-deliveries KPI being measured instead of late order deliveries. As with the case of late supplier deliveries, late order deliveries were also not useful in management's view; they were, however, able to supply estimates for the number of re-deliveries (orders that were not delivered on a given day, that had to be delivered the following day). Other KPIs, like customer complaints and variations against budget, were easily implemented as the data was readily available as portrayed in Table 8 .

\section{Variations against budget}

This measured the variation of the actual sales figures compared to the budgeted sales figures and actual labour costs compared to budgeted labour costs. For the variations 


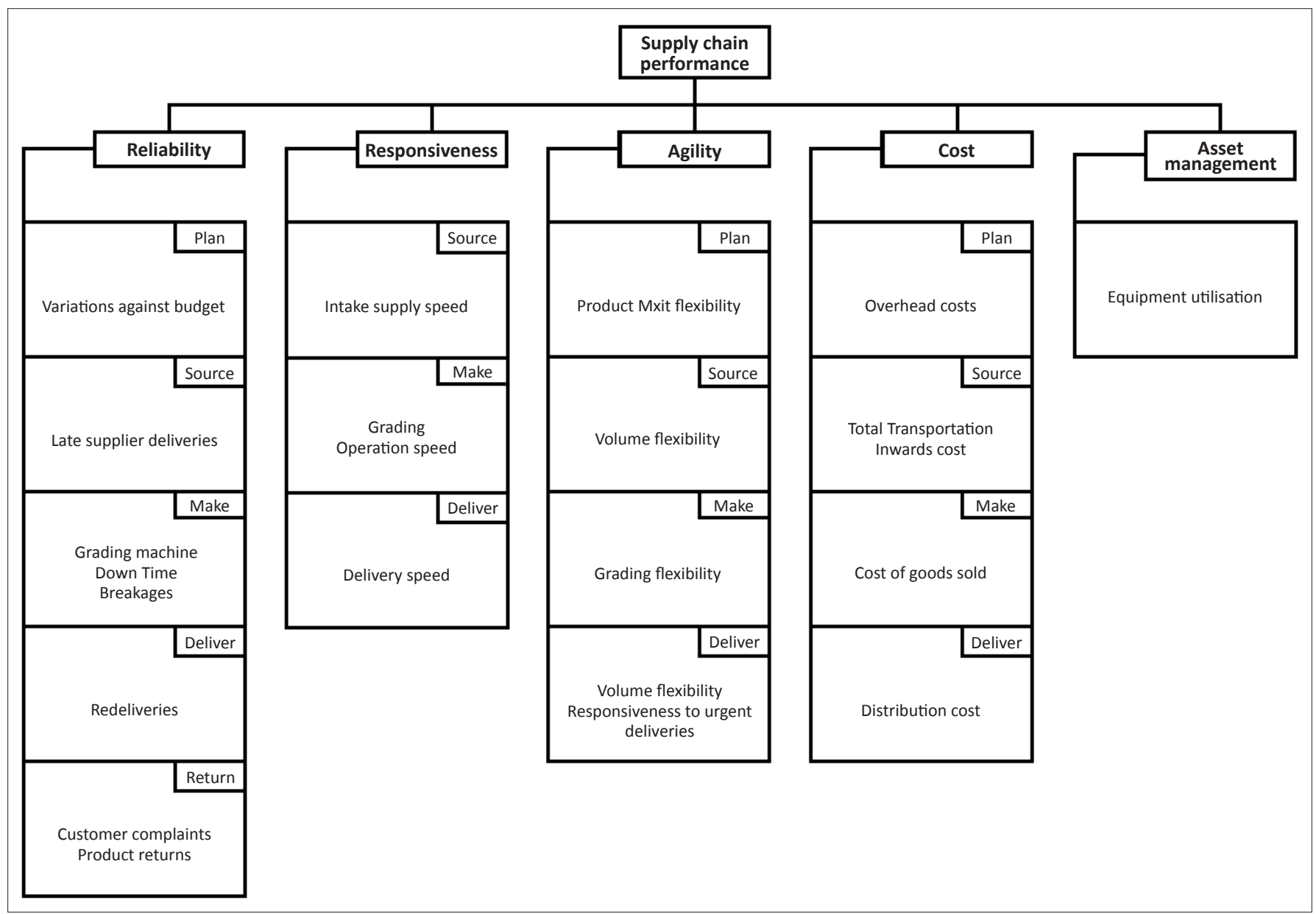

FIGURE 2: The developed model.

against budget, the performance indicator would be comparing actual wages to budgeted wages as per Table 3.

\section{Late suppliers}

Late supplier delivery is a measurement of the portion of total supplier deliveries, mostly from the farms, that arrived late per month. For the purpose of this performance measure, a supplier was classified as late if the truck arrived more than one hour later than the scheduled time. Each supplier truck thus had a one hour tolerance period within which it could arrive. Currently, there is no system in place that records the arrival times of supplier trucks, nor are they expected to arrive within a specific time slot. SA Egg's reasoning behind this is that the eggs that are offloaded from the trucks are only processed the next day, so this only becomes a problem if the truck is more than a day late. Late supplier delivery, as defined by this model, is not as important on an operational level. The target was $0 \%$ late supplier deliveries, with a rating factor of $10 \%$ of the total truck deliveries as per Table 4 .

\section{Machine down time}

Machine down-time is the fraction of time that a machine is not running out of the total scheduled running time, plus the actual running time that is unscheduled; this total is referred to as machine up-time. The machine down-time performance indicator calculation was done by averaging the actual
TABLE 3: Variations against budget: wages.

\begin{tabular}{ll}
\hline Factors & Indicator \\
\hline Variations against budget indicator & 5.3 \\
Actual costs & R5 887321.00 \\
Budget costs & R5 620803.00 \\
Variance & $4.74 \%$ \\
Target & $0.00 \%$ \\
Rating factor & $1.00 \%$ \\
\hline
\end{tabular}

TABLE 4: Late supplier deliveries.

\begin{tabular}{ll}
\hline Factors & Indicator \\
\hline Late suppliers indicator & 8.4 \\
Total truck deliveries & 161.0 \\
Trucks late & 25.0 \\
Target & $0 \%$ \\
Rating factor & $10 \%$ \\
\hline
\end{tabular}

running time for each week and dividing it by the machine up-time for each week. The actual running time and machine up-time were both calculated each week in the 'Total Grading Stats Report' as per Table 5.

\section{Breakages}

Due to the fragile nature of an egg, it is accepted that there will be some breakages, especially in the processes where eggs are handled directly. The breakages performance indicator is still an important measure however, as a sudden spike in 
this area would be indicative of problems on an operational level. The calculation of total breakages did take into account any eggs that were deliberately destroyed due to expired life, as per Table 6 . The life of an egg between farm and factory despatch was considered to be a maximum of one week.

\section{Redeliveries}

The number of orders that arrived late is not available, so the late order delivery performance indicator was replaced by redeliveries in the developed model. The definition of redeliveries is the number of deliveries that were on a given driver's route, scheduled to be delivered, but were not. These deliveries then had to be redelivered the next day, hence the name redeliveries. The information on the number of redeliveries per month is not currently being documented, due to the fact that it does not happen very often; however it can be done without difficulty as per Table 7 . The functional area in charge of redeliveries estimated that out of every 1000 deliveries, there were only three redeliveries.

\section{Customer complaints}

SA Egg receives a monthly report from their customer care centre on the feedback they receive from their customers. These are classified into two categories: product enquiries and customer complaints. General complaints vary, but in the event that there is a specific trend in customer complaints, management can be alerted to a potential problem area. Another indicator of a possible area of concern is the number of customer complaints received, as per Table 8 .

\section{Returns}

The returns performance indicator's definition is the number of products that are returned from retailers for a number of reasons. The reasons could include double orders, damaged products, wrong orders or expired products. The number of returns had an average value of around $2.0 \%$; if this value were to increase, it could be indicative of customer dissatisfaction. The target for this performance indicator was set to $1.5 \%$, with a rating factor of $0.1 \%$, as per Table 9 .

All of these processes represent the reliability leg of the developed model. SA Egg scored 70.42\% in the supply chain reliability section of the performance measurement model, as shown in Table 10.

\section{Responsiveness}

The definition of responsiveness is the speed at which the supply chain provides products to the market. In the developed model, responsiveness measured the cycle times and lead times of various steps within the supply chain process. Due to lack of information, the developed model had a different approach to measuring the speed at which products were provided to the market. The responsiveness of the supply chain was measured by the following three indicators:

- Intake supply speed

- Grading operation speed

- Delivery speed.

\section{Intake supply speed}

Intake supply speed is the speed at which the depot receives eggs from the commercial and contract farms. The speed was measured in dozens received per operational minute (dozen per minute). It was calculated as the total amount of eggs received per month in dozens, divided by the available time for deliveries per month. The available time was calculated by the 10 hours available per day, multiplied by the number of days within a month that deliveries were received as per Table 12. All of this information was gathered from the daily intake report available at the depot.

\section{Grading operation speed}

The grading operation speed is a performance indicator that measures how fast eggs move through the depot. It is not completely accurate, as it is uncertain whether the grading

\begin{tabular}{ll} 
TABLE 5: Machine down-time. & \\
\hline Factors & Indicator \\
\hline Machine down-time indicator & 5.85 \\
Average available time & $39 \mathrm{~h} 06 \mathrm{~min} \mathrm{00s}$ \\
Average down-time & $10 \mathrm{~h} 04 \mathrm{~min} 00 \mathrm{~s}$ \\
Machine down-time & $26 \%$ \\
Target & $5 \%$ \\
Rating factor & $5 \%$ \\
\hline
\end{tabular}

TABLE 6: Breakages.

\begin{tabular}{ll}
\hline Factors & Indicator \\
\hline Breakages indicator & 9 \\
Total eggs processed & 1411897 \\
Breakages & 968 \\
Breakages (\%) & $0.07 \%$ \\
Total & $0.02 \%$ \\
Rating factor & $0.05 \%$ \\
\hline
\end{tabular}

TABLE 7: Redeliveries.

\begin{tabular}{ll}
\hline Factors & Indicator \\
\hline Redeliveries indicator & 7 \\
Total deliveries & 1000 \\
Redeliveries & 3 \\
Redeliveries (\%) & $0.30 \%$ \\
Target & $0.00 \%$ \\
Rating factor & $0.10 \%$ \\
\hline
\end{tabular}

TABLE 8: Customer complaints.

\begin{tabular}{ll}
\hline Factors & Indicator \\
\hline Customer complaints performance & 5.8 \\
Number of complaints & 26 \\
Target & 5 \\
Rating factor & 5 \\
\hline
\end{tabular}

TABLE 9: Returns.

\begin{tabular}{ll}
\hline Factors & Indicator \\
\hline Returns indicator & 8.3 \\
Total deliveries & 840 \\
Deliveries returned & 14 \\
Returns (\%) & $1.67 \%$ \\
Target & $1.50 \%$ \\
Rating factor & $0.10 \%$ \\
\hline
\end{tabular}


process is a bottleneck within the depot. It is however a process through which all eggs that are received have to go, thus it is a good indicator of how many eggs go through the depot on a weekly basis. It is also the only information available for this type of calculation. For the calculations following, it was assumed that the speed (defined as the amount of eggs processed divided by the available working hours) of the grading process was the speed of all processes within the depot. The make process performance indicator was calculated by the difference between the required operating speed and the grading operating speed, as per Table 12. The more the grading operation speed matched the required speed, the higher the performance awarded to the make process performance indicator.

\section{Delivery speed}

The delivery speed performance indicator is a measure of the amount of eggs that are delivered within the available time for deliveries. The delivery speed performance indicator was calculated in the same manner as the grading speed, that is, the difference between the speed at which eggs are delivered and the speed at which they are received by the depot, as shown in Table 13.

The influencing factors on the responsiveness-performance measurement are thus: the speed at which eggs are received from the intake side of the depot and how close the speeds of grading and delivery can match this required speed set by the intake side. The combination of these three performance measures resulted in an overall value of $73.07 \%$ for the supply chain responsiveness-performance attribute, as seen in Table 14.

\section{Agility}

Supply chain agility is a performance attribute that is difficult to apply to the egg industry. The general description of supply chain agility is the ability, or the degree to which, a supply chain can match changes in demand with a supply of products. In the collection of the research available on supply chain agility there is a trend that in order for supply chains to be agile they need to move away from push-based supply chains. However, in the egg industry, the supply of eggs is continuous and the production of eggs cannot be shut down if the market is sluggish. The result is a supply chain that pushes the product from the supply side, whilst attempting to match the demand to the supply by adjusting the price. The result is for the agility leg of the performance-measurement model to focus more on flexibility, thus for the developed model, the agility leg was replaced with flexibility.

The description of supply chain agility, as it is used in the developed model, is the ability or degree to which the supply chain can supply products to customers at different levels of demand, whilst not compromising price, quality or customer service, as per Table 20.
TABLE 10: Developed model: Reliability leg.

\begin{tabular}{|c|c|}
\hline Factors & Indicator \\
\hline Source & 8.4 \\
\hline Total truck deliveries & 161 \\
\hline Trucks late & 25 \\
\hline Target & $0 \%$ \\
\hline Rating factor & $10 \%$ \\
\hline Make & 7.4 \\
\hline Machine down-time & 5.9 \\
\hline Average available time & $39 \mathrm{~h} 06 \mathrm{~min} 00 \mathrm{~s}$ \\
\hline Average down-time & $10 \mathrm{~h} 04 \mathrm{~min} 00 \mathrm{~s}$ \\
\hline Machine down-time (\%) & $26 \%$ \\
\hline Target & $5 \%$ \\
\hline Rating factor & $5 \%$ \\
\hline Deliver & 7.0 \\
\hline Total deliveries & 1000 \\
\hline Redeliveries & 3 \\
\hline Redeliveries (\%) & $0.30 \%$ \\
\hline Target & $0.00 \%$ \\
\hline Rating factor & $0.10 \%$ \\
\hline Plan & 5.3 \\
\hline Actual cost & R5 887321.00 \\
\hline Budget cost & R5 620803.00 \\
\hline Variance & $4.74 \%$ \\
\hline Target & $0.00 \%$ \\
\hline Rating factor & $1.00 \%$ \\
\hline Breakages & 9.0 \\
\hline Total eggs processed & 1411897 \\
\hline Breakages & 968 \\
\hline Breakages (\%) & $0.07 \%$ \\
\hline Target & $0.02 \%$ \\
\hline Rating factor & $0.05 \%$ \\
\hline Return & 7.1 \\
\hline Customer complaints & 5.8 \\
\hline Number of complaints & 26 \\
\hline Returns & 8.3 \\
\hline Total deliveries & 840 \\
\hline Deliveries returned & 14 \\
\hline
\end{tabular}

Note: Reliability is $70.42 \%$

TABLE 11: Intake supply speed.

\begin{tabular}{ll}
\hline Factors & Indicator \\
\hline Intake indicator & 9.07 \\
Supply speed (dozen per minute) & 96.40 \\
Required intake speed & 106.29 \\
Available time (minutes per month) & 16200 \\
Intake (dozen per month) & 1561695 \\
\hline
\end{tabular}

TABLE 12: Grading operation speed.

\begin{tabular}{ll}
\hline Factor & Indicator \\
\hline Grading operation speed (dozen per minute) & 116.809 \\
Required operational speed & 127.589 \\
Available hours per day & 8.5 \\
Available days per month & 24 \\
Available time (minutes per month) & 12240 \\
Eggs graded (dozen per month) & 1429740 \\
\hline
\end{tabular}

TABLE 13: Delivery speed.

\begin{tabular}{ll}
\hline Factors & Indicator \\
\hline Delivery speed indicator & 8.800 \\
Delivery speed (dozen per minute) & 84.843 \\
Required delivery speed & 96.401 \\
Available time (minutes per month) & 16200 \\
Eggs delivered (dozen per month) & 1374460 \\
\hline
\end{tabular}




\section{Product mix flexibility}

The product mix flexibility measures the number of different products provided by SA Egg to the Western Cape and that are processed at the Cape Town depot. An example of product mix flexibility is a car manufacturing plant that only produces two of the five models that the brand is producing. The product mix flexibility was $40 \%$. At the Cape Town depot of SA Egg, they are currently processing all 18 different products, as indicated in Table 15.

\section{Supply volume flexibility}

The supply volume flexibility-performance indicator represents the level that the current intake volume is from the maximum recorded intake volume. This indicator provides management with an idea of how far they are operating from the highest recorded intake levels. It will be directly related to the level of work that will be expected in the make and deliver processes to follow. In the implementation of this performance measure in the system, it is important to note that the maximum recorded intake volume only ranged from January 2011 to August 2011, as this was the data that was readily available. With more work, the rest of the data could be gathered and put into the system to provide a more accurate value, as per Table 16 .

\section{Production flexibility}

Production flexibility is a performance indicator that measures how close current grading volumes are to the maximum grading volumes that have been recorded to date. This again allows management to gauge the performance of the intensity of their delivery volumes. The information used in the calculation of the maximum recorded grading volume was gathered from the weekly grading report, as per Table 17.

\section{Delivery volume flexibility}

Delivery volume flexibility is a performance indicator that measures how close current delivery volumes are to the maximum level of delivery volume that has been recorded to date. This again allows management to gauge the performance of the intensity of their delivery volumes. The information used in the calculation of the maximum recorded delivery volume was gathered from the SA Egg database, where it is readily available (see Table 18).

\section{Responsiveness to urgent deliveries}

Responsiveness to urgent deliveries is a performance indicator with regards to the level of customer satisfaction the organisation provides. It measures the number of orders that an organisation is able to meet, that are requested on abnormal delivery times (mostly weekends). The actual values for this measure were not available, thus the values in Table 19 are estimates of the number of abnormal delivery requests received by the organisation on a monthly basis. The actual information could easily be captured if such a system was put into place.
TABLE 14: Developed model: responsiveness leg.

\begin{tabular}{ll}
\hline Factors & Indicator \\
\hline Source & 90.7 \\
Supply speed (dozen per minute) & 96.4 \\
Required intake speed & 106.29 \\
Available time (minutes per month) & 16200 \\
Intake (dozen per month) & 1561695 \\
Make & 9.16 \\
Grading operation speed (dozen per minute) & 116.809 \\
Required operations speed & 127.589 \\
Available hours per day & 8.5 \\
Available days per month & 24 \\
Available time (minutes per month) & 12240 \\
Eggs graded (dozen per month) & 1429740 \\
Deliver & 8.80 \\
Delivery speed (dozen per minute) & 84.843 \\
Required delivery speed & 96.401 \\
Available time (minutes per month) & 16200 \\
Eggs delivered (dozen per month) & 1374460 \\
\hline
\end{tabular}

Note: Responsiveness is $73.07 \%$

TABLE 15: Product mix flexibility.

\begin{tabular}{ll}
\hline Factors & Indicators \\
\hline Product mix flexibility indicator & 10 \\
Number of products produced & 18 \\
Number of products sold & 18 \\
Product mix (\%) & $100 \%$ \\
Rating factor & $10 \%$ \\
\hline
\end{tabular}

TABLE 16: Supply volume flexibility.

\begin{tabular}{ll}
\hline Factors & Indicator \\
\hline Volume flexibility indicator & 7.5 \\
Supply intake volume & 1561695 \\
Maximum recorded intake volume & 1785300 \\
Capacity (\%) & $87.48 \%$ \\
Rating factor & $5.00 \%$ \\
\hline
\end{tabular}

TABLE 17: Grading flexibility.

\begin{tabular}{ll}
\hline Factors & Indicator \\
\hline Production flexibility indicator & 6.3 \\
Production volume & 6028541 \\
Maximum recorded volume & 7396265 \\
Capacity (\%) & $81.51 \%$ \\
Rating factor & $5.00 \%$ \\
\hline
\end{tabular}

TABLE 18: Delivery volume flexibility.

\begin{tabular}{ll}
\hline Factors & Indicator \\
\hline Delivery volume flexibility indicator & 7.3 \\
Delivery volume & 1389856 \\
Maximum recorded delivery volume & 1606770 \\
Capacity (\%) & $86.50 \%$ \\
Rating factor & $5.00 \%$ \\
\hline
\end{tabular}

TABLE 19: Responsiveness to urgent deliveries.

\begin{tabular}{ll}
\hline Factors & Indicator \\
\hline Responsiveness to urgent deliveries indicator & 7.5 \\
Completed abnormal delivery & 54 \\
Abnormal delivery requests & 72 \\
Percentage abnormal deliveries & $75 \%$ \\
Target & $100 \%$ \\
Rating factor & $10 \%$ \\
\hline
\end{tabular}




\section{Cost}

\section{Supply chain plan cost}

The supply chain plan cost performance indicator measures the sales and marketing cost and divides it by the total number of eggs sold in dozens for each month. It is an attempt to measure some planning-related cost associated with the depot. This measure is then gauged against the average of the year-to-date (YTD). If the planning cost is equal to the average cost, a mark of $75 \%$, or 7.5 out of 10 , is awarded. If the cost is lower than the average, it is increased by a rating factor of $10 \%$ of the YTD average. This measure gauges the current month against the average of the current year and gives the ratio of the cost expenditures divided by the total number of eggs sold in dozens, as per Table 21.

\section{Supply chain transport cost}

The supply chain transport cost performance indicator measures the total inwards transport cost of the depot and divides it by the total number of eggs sold in dozens for each month. This measure is effective in gauging the cost of transporting eggs, against the number of eggs that were sold per month. The performance score out of 10 for the supply chain source cost is developed to gauge the value of the current month compared to the average YTD value. It is calculated by awarding $75 \%$, or 7.5 out of 10 , if the current value is equal to that of the average YTD value. The performance score is then increased or decreased by one point for every time the rating factor can factor into the difference of the current and average YTD values.

In this specific incident, the transportation inwards cost ratio was close to double that of the average ratio for transportation inwards cost divided by the number of eggs sold. This resulted in a -2.89 value out of 10 . This translates into paying almost double for the transportation of eggs than the average for the year. This is an alarming fact, and is represented by the resulting performance score, as per Table 22.

\section{Supply chain make cost}

The supply chain make cost performance indicator measures the total cost of the make process for the depot, and divides it by the total number of eggs sold in dozens for each month. This measure calculates how much SA Egg is currently paying for the production of the eggs sold each month. The performance score out of 10 for the supply chain make cost performance indicator is then calculated by awarding $75 \%$, or 7.5 out of 10 , if the current value for this month is equal to that of the average YTD value. The performance score is then increased or decreased by one point for every time the rating factor can factor into the difference of the current and average YTD values, as per Table 23.

\section{Supply chain delivery cost}

The supply chain delivery cost performance indicator measures the total distribution cost of the depot, and divides it by the total number of eggs sold in dozens for each month. This measure is effective in gauging the cost
TABLE 20: Developed model: Agility leg.

\begin{tabular}{ll}
\hline Attribute & Indicator \\
\hline Plan & 10.0 \\
Number of product produced & 15 \\
Number of products sold & 18 \\
Product mix & $100.00 \%$ \\
Rating factor & $10.00 \%$ \\
Source & $\mathbf{7 . 5}$ \\
Supply intake volume & 1561695 \\
Maximum recorded intake volume & 1785300 \\
Capacity (\%) & $87.48 \%$ \\
Rating factor & $5.00 \%$ \\
Make & 6.3 \\
Production volume & 6028541 \\
Maximum recorded volume & 7396265 \\
Capacity \% & $81.51 \%$ \\
Rating factor & $5.00 \%$ \\
Deliver 1 & 7.3 \\
Delivery volume & 1389856 \\
Maximum recorded delivery volume & 1606770 \\
Capacity (\%) & $86.50 \%$ \\
Rating factor & $5.00 \%$ \\
Deliver 2 & 7.5 \\
Completed abnormal delivery & 54 \\
Abnormal delivery reque & 72 \\
Percentage abnormal deliveries & $75.00 \%$ \\
Target & $100.00 \%$ \\
Rating factor & $10.00 \%$ \\
\hline
\end{tabular}

Note: Agility is $77.20 \%$

TABLE 21: Planning cost.

\begin{tabular}{ll}
\hline Factors & Indicator \\
\hline Plan cost indicator & 8.77 \\
Supply chain plan cost & R0.30 \\
Overheads: sales and market & R372 795.00 \\
Total quantity eggs sold (dozens) & 1237621 \\
Average (year to date) & R0.36 \\
Rating factor & 0.05 \\
\hline
\end{tabular}

TABLE 22: Transport cost.

\begin{tabular}{ll}
\hline Factors & Indicator \\
\hline Transport cost indicator & -2.89 \\
Supply chain transport cost & R0.79 \\
Transport inwards & R976 532.00 \\
Total quantity eggs sold (dozens) & 1237621 \\
Average (year to date) & R0.33 \\
Rating factor & 0.04 \\
\hline
\end{tabular}

TABLE 23: Make cost.

\begin{tabular}{ll}
\hline Factors & Indicator \\
\hline Make cost indicator & 7.48 \\
Supply chain make cost & R10.22 \\
Raw material & R1 012453.00 \\
Direct production costs & R2 469 734.00 \\
Indirect production costs & R53 545.00 \\
Total quantity eggs sold (dozens) & 1237621 \\
Average (year to date) & R10.19 \\
Rating factor & 1.36 \\
\hline
\end{tabular}

TABLE 24: Delivery cost.

\begin{tabular}{ll}
\hline Factors & Indicator \\
\hline Delivery cost indicator & 8.07 \\
Supply chain delivery cost & R0.38 \\
Distribution costs & R46 849.00 \\
Total quantity eggs sold (dozen) & 1237621 \\
Average (year to date) & R0.41 \\
Rating factor & 0.05 \\
\hline
\end{tabular}


of distributing eggs in a month, against the number of eggs that were sold in that month. The performance score out of 10 for the supply chain delivery cost is developed to gauge the value of the current month compared to the average YTD value. It is calculated by awarding $75 \%$, or 7.5 out of 10 , if the current value is equal to that of the average YTD value. The performance score is then increased or decreased by one point for every time the rating factor can factor into the difference of the current and average YTD values, as per Table 24 .

The final presentation of the cost leg of the developed model is represented in Table 25, displaying a performance of $53.56 \%$ for the cost section of the model. The average score for the planning, make and deliver processes was above $80.00 \%$. However, the severe increase in the transport cost is the reason for the dramatic drop in the overall performance score of the cost leg.

\section{Asset management}

Due to a lack of financial information, the KPIs suggested by the proposed model were not included in the developed model. Instead, equipment utilisation was measured, as it was the only practical performance measure available at the Cape Town depot.

\section{Equipment utilisation}

Equipment utilisation should not be confused with the equipment reliability performance measure. Equipment reliability measures the portion of the time that equipment is used when it is supposed to be used, whereas equipment utilisation measures the percentage of time that equipment is used compared to the available time. It is calculated by determining the amount of time that equipment is available for use, compared to the time that equipment is actually used, as per Table 26. The asset management in the developed model was calculated to be $74.55 \%$.

\section{The final dashboard}

A brief overview of the final dashboard is presented in Figure 3, whilst the actual interface is shown in Figure 4. The overall supply chain performance scored a mark of $69.87 \%$ for the month of August 2011. By selecting the range of months from dropdown lists, in this case from January 2011 to August 2011, the performance measurement system selected the relevant data from the monthly reports that were available to SA Egg's managerial staff. The output was then calculated according to the performance indicators discussed for the overall supply chain performance as well as for each performance attribute for the latest month selected in the range.

The output of each performance attribute is also presented in a graph for the selected time frame. As in Figure 3, the dashboard shows: (1) the tracking of the supply chain's performance, over the selected time period; (2) the overall performance of the supply chain, calculated as the average
TABLE 25: Final representation of the cost leg of the developed model.

\begin{tabular}{ll}
\hline Factors & Indicator \\
\hline Source & $\mathbf{- 2 . 8 9}$ \\
Supply chain source cost & $\mathrm{R} 0.79$ \\
Transport inwards & $\mathrm{R} 976532.00$ \\
Total quality eggs sold (dozens) & 1237621 \\
Average (year to date) & $\mathrm{R} 0.33$ \\
Rating factor & 0.04 \\
Make & $\mathbf{7 . 4 8}$ \\
Supply chain make cost & $\mathrm{R} 10.22$ \\
Raw material & $\mathrm{R} 1012453.00$ \\
Direct Production cost & $\mathrm{R} 2469734.00$ \\
Indirect production cost & $\mathrm{R} 53545.00$ \\
Total quality eggs sold (dozens) & 1237621 \\
Average (year to date) & $\mathrm{R} 10.19$ \\
Rating factor & 1.36 \\
Plan & $\mathbf{8 . 7 7}$ \\
Supply chain plan cost & $\mathrm{R} 0.30$ \\
Overheads- sales and marketing & $\mathrm{R} 372795.00$ \\
Total quality eggs sold (dozens) & 1237621 \\
Average (year to date) & $\mathrm{R} 0.36$ \\
Rating factor & 0.05 \\
Deliver & $\mathbf{8 . 0 7}$ \\
Supply chain plan cost & $\mathrm{R} 0.38$ \\
Distribution costs & $\mathrm{R} 46489$ \\
Total quality eggs sold (dozens) & 1237621 \\
Average (year to date) & $\mathrm{R} 0.41$ \\
Rating factor & 0.05 \\
\hline
\end{tabular}

Note: Cost is $53.56 \%$

TABLE 26: Equipment utilisation.

\begin{tabular}{ll}
\hline Factors & Indicator \\
\hline Equipment utilisation indicator & 7.456 \\
Available time & $40 \mathrm{~h} 00 \mathrm{~min} 00 \mathrm{~s}$ \\
Actual time & $32 \mathrm{~h} 54 \mathrm{~min} 39 \mathrm{~s}$ \\
Utilisation & $82.28 \%$ \\
Target & $95.00 \%$ \\
Rating factor & $5.00 \%$ \\
\hline
\end{tabular}

of the five performance attributes; (3) the dropdown lists used to select the range of the time periods (in months); (4) the individual performances of each of the five performance attributes; (5) the tracking of the five performance attributes over the selected time period; (6) the display of a summary of each performance for the month.

Note that these numerical values are arbitrary, and consequently the final score is also arbitrary. However, this does not negate the method; it still serves as a method that provides a good relative comparison between supply chain variables.

The dashboard presented to, and used by management may be condensed, as per Figure 4.

For a concise dashboard, as preferred by management, and for clarity purposes, item 6 from Figure 4, has been removed.

\section{Conclusions and further research}

There are a number of limitations to the model; some are theoretical limitations (such as the relativity of the rating 
factors per attribute) that will require the model to be redesigned or altered until it represents a fair indication of the business environment. However, in general, the implemented model captures the trend of the different performance attributes of the supply chain. It is important to note that the implemented model was tailored from the

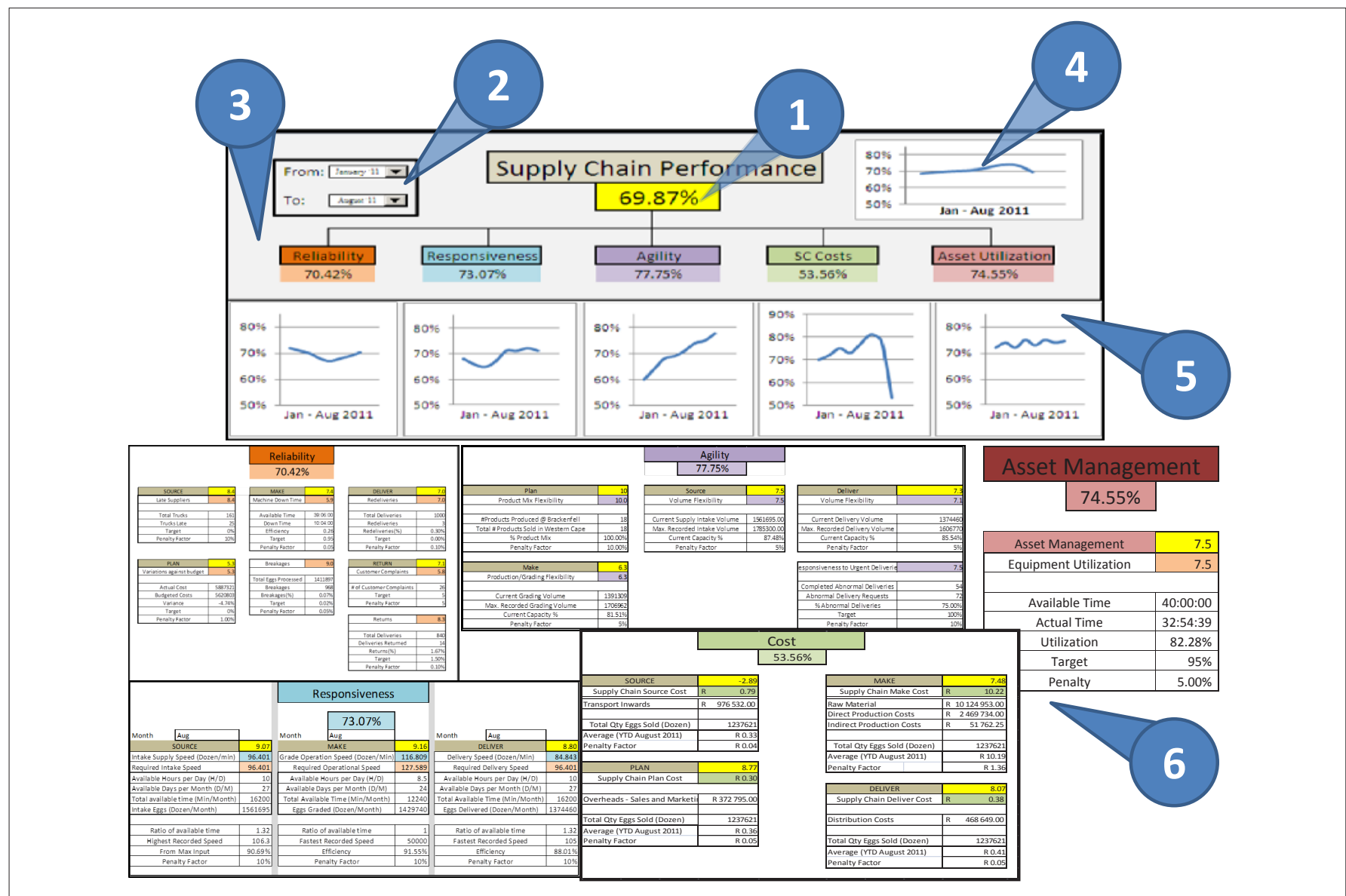

1 , The tracking of the supply chain's performance over the selected time horizon; 2 , The overall performance of the supply chain, calculated as the average of the five performance attributes; 3 , The dropdown lists to select the range of the time horizon in months; 4 , The individual performances of each of the five performance attributes; 5 , The tracking of the five performance attributes over the selected time horizon; 6 , The display of a summary of each performance for the month.

FIGURE 3: Interface layout of the dashboard.

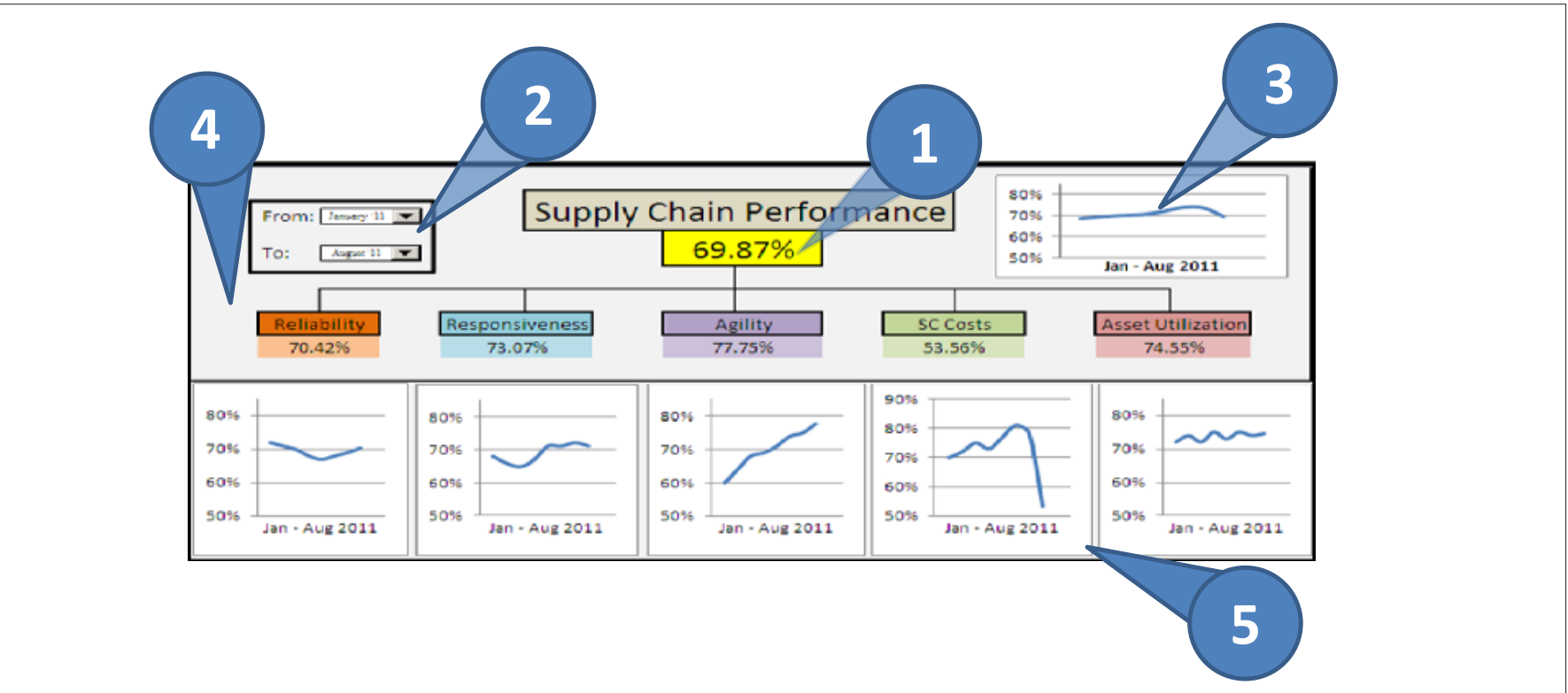

1 , The tracking of the supply chain's performance over the selected time horizon; 2 , The overall performance of the supply chain, calculated as the average of the five performance attributes; 3 , The dropdown lists to select the range of the time horizon in months; 4 , The individual performances of each of the five performance attributes; 5 , The tracking of the five performance attributes over the selected time horizon.

FIGURE 4: A final dashboard format for management. 
information that was available to management on a regular basis. This model was created to show an example of the theoretical model in practice, and requires a supply chain manager with expertise and who can monitor and adjust the values of each attribute to achieve the organisations' strategic aims.

The prototype allowed SA Egg to compare their supply chain with other supply chains in the same industry and other industries. It is possible to change the weighting of certain measures by changing the rating factors for each performance indicator. This can be done to increase the contribution of a specific attribute. The final performance of the supply chain, as well as the five different performance attributes, is presented in a dashboard in Microsoft Excel that uses the information provided to management on a periodical basis. As stated originally, the emphasis can now be broadened from a purely functional approach to a comprehensive supply-chain approach.

The road ahead for SA Egg: it is proposed that the model be reviewed, and used as a guideline to install systems that capture the data that the ideal performance-measurement system requires. After the required data is available, the performance-measurement system can be implemented and will represent a more accurate indicator of the performance of the supply chain. Once this has been established, management will be well situated to introduce the complete SCOR system. SA Egg is in a fortunate position, in that they are already in control of most of their supply chain; this greatly increases the opportunity for effective supply chain management. Although they are part of a supply chain it has become obvious during the research that many parts of the supply chain are not being tested and/or measured, and are therefore not managed. This model will be used as a foundation for future studies, to develop an improved version, not only for the egg industry, but for other industries as well. The model serves to facilitate the transition from localised and functional management control to a supply chain wide management participation and approach before engaging in a full-scale SCOR implementation.

\section{Acknowledgements Competing interests}

The authors declare that they have no financial or personal relationship(s) that may have inappropriately influenced them in writing this article.

\section{Author contributions}

G.R. (University of Stellenbosch) was responsible for $40 \%$ of the writing of the article whilst C.P. (University of Stellenbosch) and K.v.L. (University of Stellenbosch) were each responsible for $30 \%$ of the remainder of the article.

\section{References}

Ayers, J.B., 2006, Handbook of Supply Chain Management (2nd edn.), CRC Press, USA. Bullinger, H-J., Kühner, M. \& Van Hoof, A., 2002, 'Analysing supply chain performance using a balanced measurement', International Journal of Production Research, 40 (15), 3533-3543. http://dx.doi.org/10.1080/00207540210161669

Chabaane, A, 2011, Multi-criteria methods for designing and evaluating sustainable supply chains, in partial fulfilment of the requirements for the degree of doctor of philosophy, Montreal, Canada, p. 36.

Gunasekaran, A., Patel, C. \& McGaughey, R.E., 2004, 'A framework for supply chain performance measurement', International Journal of Production Economics, 87 (3), 333-347. http://dx.doi.org/10.1016/j.ijpe.2003.08.003

Huang, S.H., Sheoran, S.K. \& Keskar, H., 2005, 'Computer-assisted supply chain configuration based on supply chain operations reference (SCOR) model', Computers \& Industrial Engineering 48 (2), 377-394. http://dx.doi.org/10.1016/j. computers \& In 2005.01 .001

Kaplan, R.S. \& Norton, D.P., 1992, 'The balanced scorecard - Measures that drive performance', Harvard Business Review, 71-79.

Lohman, C., Fortuin, L. \& Wouters, M., 2004, 'Designing a performance measurement system: A case study', European Journal of Operational Research 156 (2), 267286. http://dx.doi.org/10.1016/S0377-2217(02)00918-9

Shepherd, C. \& Günter, H., 2005, 'Measuring supply chain performance: Current research and future directions', International Journal of Productivity and Performance Measurement 55(3), 242-258.

Supply Chain Council, 2012, Supply Chain Council (SCC) publishes SCOR 11, December 01, 2012. http://supply-chain.org/news-scor-11-release

Van der Vorst, J.G.A.J., 2000, Effective food supply chains: Generating, modelling and evaluating supply chain scenarios, pp. 50-53, PhD-thesis, Wageningen University, viewed 11 June 2011, from http://www.library.wur.nl/wda/dissertations/dis2841. pdf 